symptom onset. Recently, isolation and precautions of an ICU patient hospitalized beyond 20 days of symptom onset were removed by infection control advisers based on Centers for Disease Control and Prevention (CDC) recommendations that patients with more severe to critical illness or severe immunocompromise likely remain infectious no longer than 20 days after symptom onset, and extending duration of isolation and precautions for up to 20 days after symptom onset for severe cases is warranted. ${ }^{4}$ A 46 -year-old female patient with a past medical history of essential hypertension initially presented with fever, shortness of breath, diarrhea, and cough. She tested positive for SARS-CoV-2 and required medical ICU care for multi-organ failure secondary to COVID-19. Isolation precautions were removed on day 21 of her symptom onset. Examination, medication administration, and procedures including terminal extubation were performed without precaution until her death 25 days after onset of symptoms. Notably, a repeated SARSCoV-2 PCR test on day 23 of her symptoms was positive. After ending the isolation precautions, 1 ICU resident developed fever, cough, and shortness of breath within 2 days after exposure and tested positive for SARS-CoV-2. She is currently hospitalized for severe COVID-19. In addition, 3 ICU nurses also tested positive for SARS-CoV-2, with symptoms of cough, fever, anosmia, and dysgeusia. Furthermore, 3 of 5 other ICU residents developed transient mild symptoms, including diarrhea, cough, and myalgia within 2-7 days after exposure, but they were not tested for SARS-CoV-2. These staff members did not have any other known exposure to SARS-CoV-2. Universal masking, eye protection, gowning, gloves, hair cover, and shoe covers were implemented for all patient encounters, and appropriate personal protective equipment was used for patients with suspected or confirmed COVID-19.

COVID-19 patients who have been infectious for $>20$ days have been reported in a peer-reviewed journal, ${ }^{5}$ and severe COVID-19 infection has been associated with prolonged viral shedding. ${ }^{6} \mathrm{WHO}$ recommendations on isolation cited the range of viral shedding as $0-20$ days from a personal communication published on a preprint website instead of in a peer-reviewed journal, ${ }^{7,8}$ or from a study of asymptomatic patients ${ }^{9}$ or animal models. ${ }^{10}$ In the setting of an unprecedented global pandemic, this reckless recommendation on ending isolation and precautions may put frontline healthcare workers at an unnecessary higher risk of being infected and thus may exacerbate critical staff shortages. Using an abundance of caution, we should rethink the recommended criteria for releasing COVID-19 patients from isolation.

\section{References}

1. Guddati A. Protection of healthcare professionals during an epidemic: medical, ethical, and legal ramifications. Interact J Med Res 2020; 9:e19144.

2. Rhee C, Baker MA, Klompas M. The COVID-19 infection control arms race. Infect Control Hosp Epidemiol 2020. doi: 10.1017/ice.2020.211.

3. Sarmadi M, Kakhki S, Foroughi M, et al. Hospitalization period of COVID-19 for future plans in hospital. Br J Surg 2020. doi: 10.1002/ bjs.11871.

4. Duration of isolation and precautions for adults with COVID-19. Centers for Disease Control and Prevention website. https://www.cdc.gov/ coronavirus/2019-ncov/hcp/duration-isolation.html. Accessed November 30, 2020.

5. Avanzato VA, Matson MJ, Seifert SN, et al. Case study: prolonged infectious SARS-CoV-2 shedding from an asymptomatic immunocompromised individual with cancer. Cell 2020. doi: 10.1016/j.cell.2020.10.049.

6. Lu Y, Li Y, Deng W, et al. Symptomatic infection is associated with prolonged duration of viral shedding in mild coronavirus disease 2019: a retrospective study of 110 children in Wuhan. Pediatr Infect Dis J 2020;39:e95-e99.

7. Criteria for releasing COVID-19 patients from isolation. World Health Organization website. https://www.who.int/publications/i/item/criteriafor-releasing-covid-19-patients-from-isolation. Published 2020. Accessed November 30, 2020.

8. Lu J, Peng J, Xiong Q, et al. Clinical, immunological and virological characterization of COVID-19 patients that test re-positive for SARS-CoV-2 by RT-PCR. Medrxiv 2020. doi: 10.1101/2020.06.15.20131748. (Preprint.)

9. Zhou R, Li F, Chen F, et al. Viral dynamics in asymptomatic patients with COVID-19. Int J Infect Dis 2020;96:288-290.

10. Sia SF, Yan LM, Chin AWH, et al. Pathogenesis and transmission of SARS-CoV-2 in golden hamsters. Nature 2020;583:834-838.

\title{
Assessing the infection risk of a vertical garden in a hospital setting
}

\author{
Bernard Surial MD ${ }^{1}$ (1) , Miriam Vázquez MD $^{1}$, Walter Steiger ${ }^{1}$, Eveline Rolli ${ }^{1}$, Simon Brand ${ }^{2}$, Konrad Mühlethaler MD, MSc ${ }^{3}$ \\ and Jonas Marschall MD, MSc ${ }^{1}$ (1) \\ ${ }^{1}$ Department of Infectious Diseases, Bern University Hospital, University of Bern, Bern, Switzerland, ${ }^{2}$ Infrastructure Directorate, Bern University Hospital, Bern, \\ Switzerland and ${ }^{3}$ Institute for Infectious Diseases, University of Bern, Bern, Switzerland
}

To the Editor-Although being exposed to nature may accelerate healing and enhance patients' well-being, ${ }^{1}$ organic material and water sources in healthcare institutions can be harmful. ${ }^{2}$ There

Author for correspondence: Jonas Marschall, E-mail: Jonas.marschall@insel.ch PREVIOUS PRESENTATION. These results were presented at the annual meeting of the Swiss Society for Hospital Hygiene in Lausanne, Switzerland, September 2019.

Cite this article: Surial B, et al. (2022). Assessing the infection risk of a vertical garden in a hospital setting. Infection Control \& Hospital Epidemiology, 43: 273-275, https://doi.org/ 10.1017/ice.2020.1421 is little evidence on the impact of indoor gardens in healthcare settings; thus, we evaluated the potential for environmental contamination of an indoor plant wall from the time of its construction on to assess its risk for patient safety.

In 2016, an addition to our hospital was planned that included a windowless, $11-\mathrm{m}^{2}\left(118 \mathrm{ft}^{2}\right)$ waiting area next to the physical therapy rooms. Together with an interior designer and the infection prevention team, a "vertical garden" was conceived and installed on one of the waiting area's walls and then assessed before the building was opened 


\section{Surrounding air}
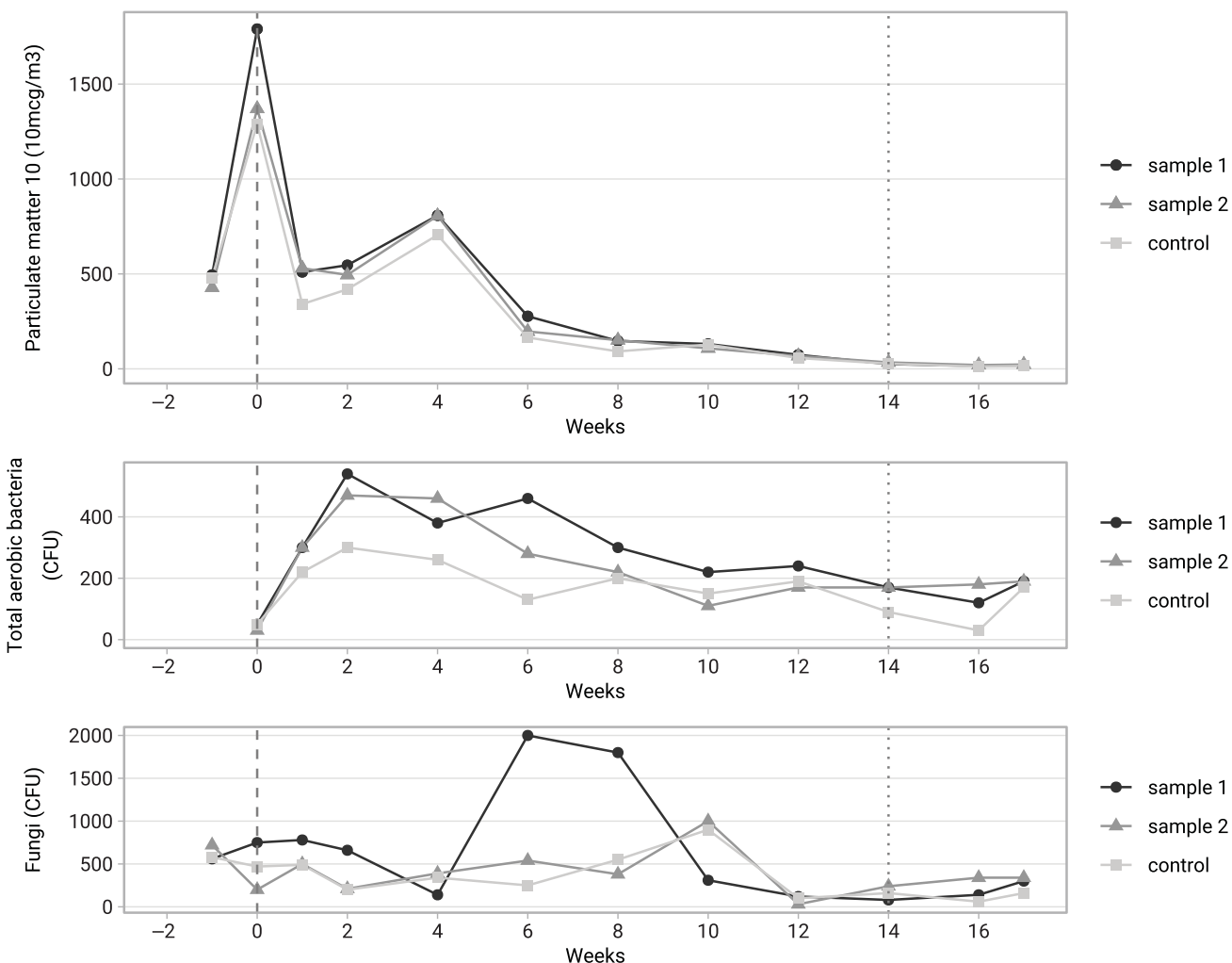

Direct measurement on plant wall

Fig. 1. Particulate matter, total aerobic bacteria and fungi measurements of the vertical garden and its surroundings. Sample 1 was taken next to the wall, sample 2 was taken $10 \mathrm{~m}$ away from the wall, and the control measurement was taken in an adjacent room. Measurements denoted as location 1 were taken in the upper third of the wall, those denoted as location 2 in the middle of the wall, and those described as location 3 in the lower third of the wall.

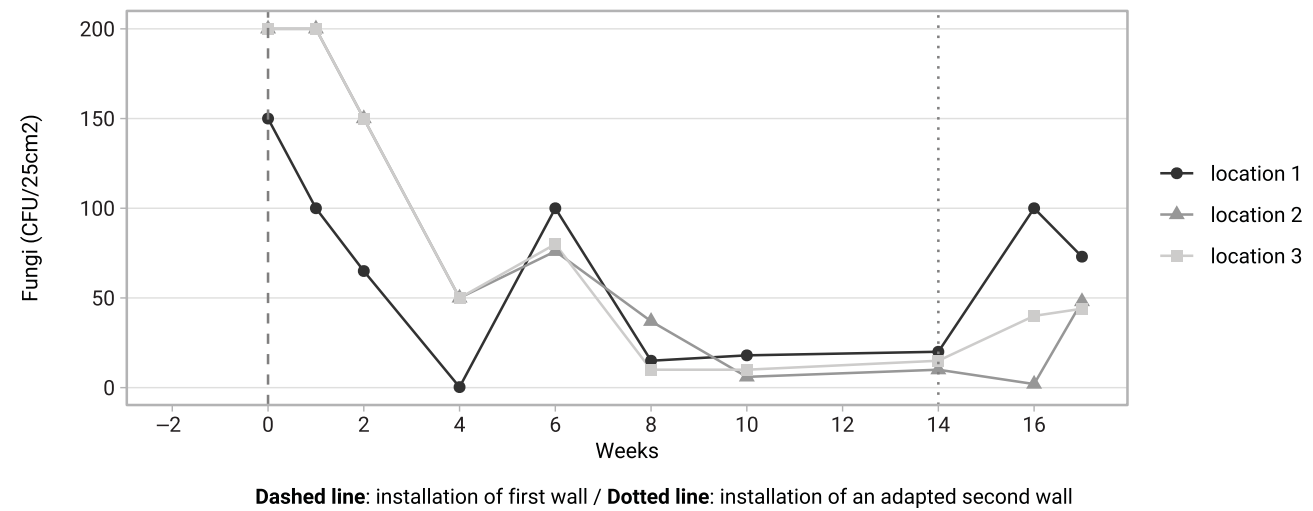

for patients. The plants (including Peperomia spp, Cryptanthus bivittatus, Pellionia repens, Philodendron scandens, Begonia rex, and Microsorum diversifolium) were inserted into a $6-\mathrm{m}^{2}\left(65 \mathrm{ft}^{2}\right)$ polyethylenterephthalate net and irrigated with a water-loop system with a covered tank above and a water ditch below the wall. Using a microbial air sampler, particulate matter (PM-10) was measured in the surrounding air, and total aerobic bacterial counts and yeast and molds in the air were assessed using agar strips with tryptic soy and Sabouraud dextrose agar. To account for cross-contamination by other sources, we performed control measurements in the adjacent room. Aspergillus spp in the air was identified by microscopy and matrix-assisted laser desorption/ionization time-of-flight mass spectroscopy (MALDI-TOF MS). Irrigation water was tested for total aerobic bacteria, Pseudomonas spp, Legionella spp following current industry norms, and mycobacteria as described previously. ${ }^{3}$ Wallsurface cultures were performed using contact plates containing tryptic soy agar (for total aerobic bacteria) and dichloran glycerol and chloramphenicol (for yeast and molds). After the first results, the wall was rebuilt with a different set of Tillandsia and succulent plants and a reduced water irrigation in an attempt to minimize the contamination. Assessments were repeated as outlined above. The hospital's infrastructure directorate approved the study and funded diagnostic testing. No institutional review board approval was required for this quality improvement project.

Measurements were performed every 14 days from 1 week before the installation of the first wall until 3 weeks after the modified wall was placed. Visual inspection revealed dust on the plant leaves and presence of flies (Drosophila spp) after 4 weeks, and biofilm formation in the water irrigation tank 6 weeks after the first wall was constructed. The results of measurements for particulate matter, bacterial and fungal burden of the surrounding air, and direct measurements on the plant wall are shown in Figure 1. We found no increases in particulate matter over time, but we encountered high concentrations in weeks 1 and 2 due to ongoing 
construction work in the waiting area. After the installation of the first wall, increased concentrations of total aerobic bacteria counts and yeasts and molds were detectable in the surrounding air. There was no detectable Aspergillus spp, which could be attributed to the first wall; however, we identified Aspergillus terreus in the air 2 weeks after the installation of the modified wall. Direct measurements on the wall indicated an abundance of aerobic bacteria throughout the observations. Fungi were present on plant material throughout the study period, and Aspergillus niger was isolated in 2 different samples at week 10. After the modification of the plant wall, fungal concentrations were lower than before, but total aerobic bacterial counts of the surrounding air remained elevated. In the water tank, total aerobic bacterial counts were between 150 and 3,000 CFU, with the presence of Pseudomonas spp detected in only 1 instance and no Legionella spp identified. In the draining water, neither Pseudomonas spp nor Legionella spp were present, but we identified abundant Mycobacterium avium complex, especially early after installation of the first wall.

In the present study, we evaluated an element of modern healthcare design intended to provide an enjoyable patient experience. After installing the indoor vertical garden, we detected elevated concentrations of bacteria and fungi in the air and on the wall, which could act as a source for nosocomial transmissions.

Studies on the role of plants in patient-care areas mainly assessed the impact of flowers in ornamental vases. High concentrations of gram-negative bacteria could be detected in the water inside the vases, but their relevance for nosocomial infections among immunocompetent individuals remains unclear. ${ }^{4}$ Invasive fungal infections with Aspergillus spp and Fusarium spp in immunocompromised individuals have been linked to the presence of fungi in the soil of potted plants, ${ }^{5,6}$ and waterborne outbreaks due to Pseudomonas aeruginosa and Legionella pneumophila arising from water outlets and decorative fountains have been well described. ${ }^{2,7,8}$

This study has several limitations. First, we were unable to evaluate whether our findings represent an increased risk for nosocomial infections. Second, cross-contamination could have occurred due to ongoing construction works, which ended during the second wall's assessment period. However, finalizing these construction works did not affect the measurements. Finally, the building had not dried entirely, and measurements were performed in an area that was not well ventilated, both of which might have increased the likelihood of microbial contamination. Nevertheless, relative humidity of the waiting area was within recommended norms throughout the study period.
In conclusion, the elevated concentrations of microorganisms in the air, on the plant wall, and in the water of this vertical garden led the hospital's infection prevention committee to forego any further indoor plant installations. Building projects of indoor gardens in hospitals should be evaluated carefully to assess the potential for environmental contamination to prevent nosocomial infections.

Supplementary material. To view supplementary material for this article, please visit https://doi.org/10.1017/ice.2020.1421

Acknowledgments. We greatly appreciate Prof Jean Odermatt (Bern University of the Arts) for the development of the design concept, and Stefan Müller (head gardener, Bern University Hospital) for the implementation and support of the plant wall. The vertical wall was designed by Hydroplant (Moritz Küderli), and Michael Hagenauer constructed and entertained the plant wall. RhenoControl $\mathrm{GmbH}$ supplied the water irrigation system.

Financial support. We thank the Infrastructure Directorate for funding the diagnostic tests.

Conflicts of interest. All authors report no conflicts of interest relevant to this article.

\section{References}

1. Ulrich RS. View through a window may influence recovery from surgery. Science 1984;224:420-421.

2. Anaissie EJ, Penzak SR, Dignani MC. The hospital water supply as a source of nosocomial infections: a plea for action. Arch Intern Med 2002;162: 1483-1492.

3. Schreiber PW, Kohler N, Cervera R, Hasse B, Sax H, Keller PM. Detection limit of Mycobacterium chimaera in water samples for monitoring medical device safety: insights from a pilot experimental series. J Hosp Infect 2018;99:284-289.

4. Taplin D, Mertz PM. Flower vases in hospitals as reservoirs of pathogens. Lancet 1973;2:1279-1281.

5. Lass-Florl C, Rath P, Niederwieser D, et al. Aspergillus terreus infections in hematological malignancies: molecular epidemiology suggests association with in-hospital plants. J Hosp Infect 2000;46:31-35.

6. Rogues AM QC, Revel P, Saric J, Gachie JP. Potted plants as a potential reservoir of Fusarium species. J Hosp Infect 1997;35:163-164.

7. Palmore TN, Stock F, White M, et al. A cluster of cases of nosocomial legionnaires disease linked to a contaminated hospital decorative water fountain. Infect Control Hosp Epidemiol 2009;30:764-768.

8. Hlady WG, Mullen RC, Mintz CS, Shelton BG, Hopkins RS, Daikos GL. Outbreak of Legionnaire's disease linked to a decorative fountain by molecular epidemiology. Am J Epidemiol 1993;138:555-562. 